\title{
Cooperation of Tomsk Polytechnic University with European Universities of Technology
}

\author{
Alexander I. Chuchalin \\ National Research Tomsk Polytechnic University, Tomsk, 30, Lenin Av., 634050, Russian Federation
}

\begin{abstract}
The paper represents a case-study describing 20 year experience of Tomsk Polytechnic University, one of the leading Russian engineering schools, in developing international cooperation with leading European universities of technology. The concept, strategy and priorities of the University international cooperation are discussed. The results of cooperation in three main areas (joint research projects, joint (double/dual) degree programs and students' academic mobility) are given in the paper. The international cooperation is considered to be an instrument for improvement of quality of research and education at the University.
\end{abstract}

Keywords International Cooperation, Joint Research Projects, Joint Degree Programs, Students' Academic Mobility, Quality of Research And Education

\section{Introduction}

Globalization of the world economy fosters internationalization in different spheres of human activity, including research and higher education. More and more researchers, professors and managers of Russian universities realize the fact that Russian higher education institutions (HEIs) are being involved in international cooperation. Tomsk Polytechnic University (TPU) recognized the importance and the need for internationalization of education and science in early 1990s. For 20 years the University has been actively involved in international cooperation with leading universities of Europe.

\section{TPU International Cooperation: Concept, Strategy and Priorities}

During the Soviet time, being the oldest university center in the Asian part of Russia, Tomsk was closed to foreign countries and hence, all HEIs, including Tomsk Polytechnic University had limited opportunities for development of international cooperation. First steps towards internationalization of science and education at TPU were made in 1991. By the beginning of the $21^{\text {st }}$ century the University was ready for implementation of Development Plan (DP) for 2001-2005 with the main objective of integration the University into the world scientific and educational community.

* Corresponding author:

chai@tpu.ru (Alexander I. Chuchalin)

Published online at http://journal.sapub.org/edu

Copyright (C) 2012 Scientific \& Academic Publishing. All Rights Reserved
Within the framework of DP-2005 a number of target programs aimed at students and faculty foreign language training, expansion of international cooperation with leading European universities and research centers, recruiting of international students, etc., have been successfully implemented. At present TPU has a status of a National Research University and is considered one of the leading technical universities in Russia occupying the $2^{\text {nd }}$ position in the official ranking of the Russian Federation Ministry of Education and Science among more than 160 higher engineering schools.

The concept of TPU international activity is based on the following ideas:

1. International cooperation is considered to be an efficient tool for education and research quality improvement and ensuring the University's worldwide competitive performance in priority fields.

2. Development of international cooperation in education and research is an integral part of University evolution and a key element of the implementation of its mission.

3. International cooperation outcomes are planned and achieved using all kinds of University resources: human, financial, information and managerial resources.

4. International cooperation planning is based on 2009-2018 Development Plan of TPU as a National Research University integrated into international education and research community.

5. International cooperation embraces all institutes, faculties and departments of TPU. Heads of divisions take personal responsibility for management and outcomes of their international activity.

6. The University has special department in charge of organization and monitoring of international cooperation outcomes, as well as their impact on the quality of research 
and education, worldwide competitive performance, development of strategy and major fields of TPU international affairs and key indicators of its efficiency.

Strategic goal of international activity is positioning of the University as an internationally recognized center for research and higher education, training specialists able to meet the world standards in compliance with the TPU mission and DP for 2009-2018 [11].

Priorities of TPU international activity are as follows:

1. Monitoring of global trends in research and higher education, study and use of the advanced international experience.

2. Internationalization and development of research and education resources in compliance with global trends (in 2010 institutional projects in the framework of such international programs as TEMPUS (3), FP7 (3), ERASMUS $M U N D U S$ (1) and 80 international projects under individual grants had been implemented at TPU).

3. Presentation of research and education achievements at international conferences and exhibitions (in 2010 TPU won 25 medals and was awarded with 30 certificates of international exhibitions, $21 \mathrm{TPU}$ students were awarded for participation in international competitions).

4. Publication of research and development results abroad (733 (33\%) papers of TPU staff and students were published abroad in 2010).

5. International accreditation and certification of academic programs and high-tech products $(8$ academic programs of TPU were awarded with the EUR-ACE Label in 2010).

6. Export of research and education products and services abroad (in 2010 TPU carried out research meeting the interest of foreign companies for the amount of over $€ 3 \mathrm{mln}$ $(13 \%)$, and provided education services to international students for the amount of $€ 2 \mathrm{mln}(15 \%)$.

7. International academic exchanges (607 (18\%) TPU employees participated in internships, professional development programs, research activities and lectures delivery abroad, 420 TPU full-time students (2\%) had part of their studies in the partner universities as exchange students, 107 international students studied at TPU in the framework of academic exchange programs in 2010).

8. Education of international students and post-graduates (in 2010 over 2000 full-time international students and post-graduates (16\%) from 30 countries studied at TPU).

9. Organization of international symposiums, conferences, seminars (47 international conferences and seminars with more than 7500 participants were held at TPU in 2010).

10. Development of multicultural University environment for international cooperation.

11. Development of the University website in foreign languages (English, German, Chinese).

12. University positioning in world rankings (in 2010 TPU held $57^{\text {th }}$ position in Webometrics-ranking of Top- 100 within Central and Eastern Europe).

At present, TPU has cooperation agreements on education and research with 130 universities of 30 countries worldwide, including 73 agreements with European universities.

One of the University's priorities is the development of cooperation with foreign partners within international associations and consortiums. TPU is a member of dozen international organizations (EUA, EAIE, EARMA, ENQHEEI, IGIP, SEFI, T.I.M.E., etc.).

It should be noted that since 2005 TPU has been the only Russian university - member of Conference of European Schools for Advanced Engineering Education and Research (CESAER) and associated member of Consortium Linking Universities of Science and Technology for Education and Research (CLUSTER) - organizations uniting leading European universities of technology. Tomsk Polytechnic University is developing bilateral cooperation with 23 universities out of 57 being included in CESAER, and with 9 universities out of 12 being CLUSTER members.

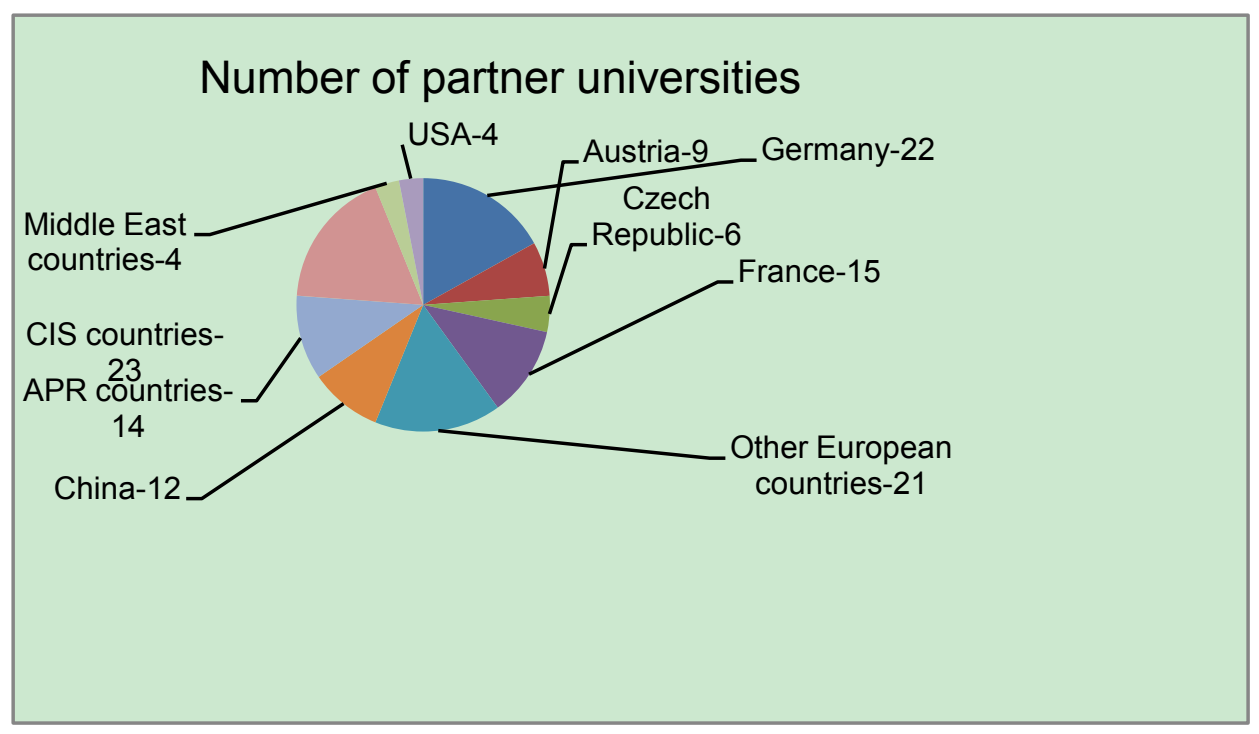

Figure 1. Number of TPU partner universities by countries 


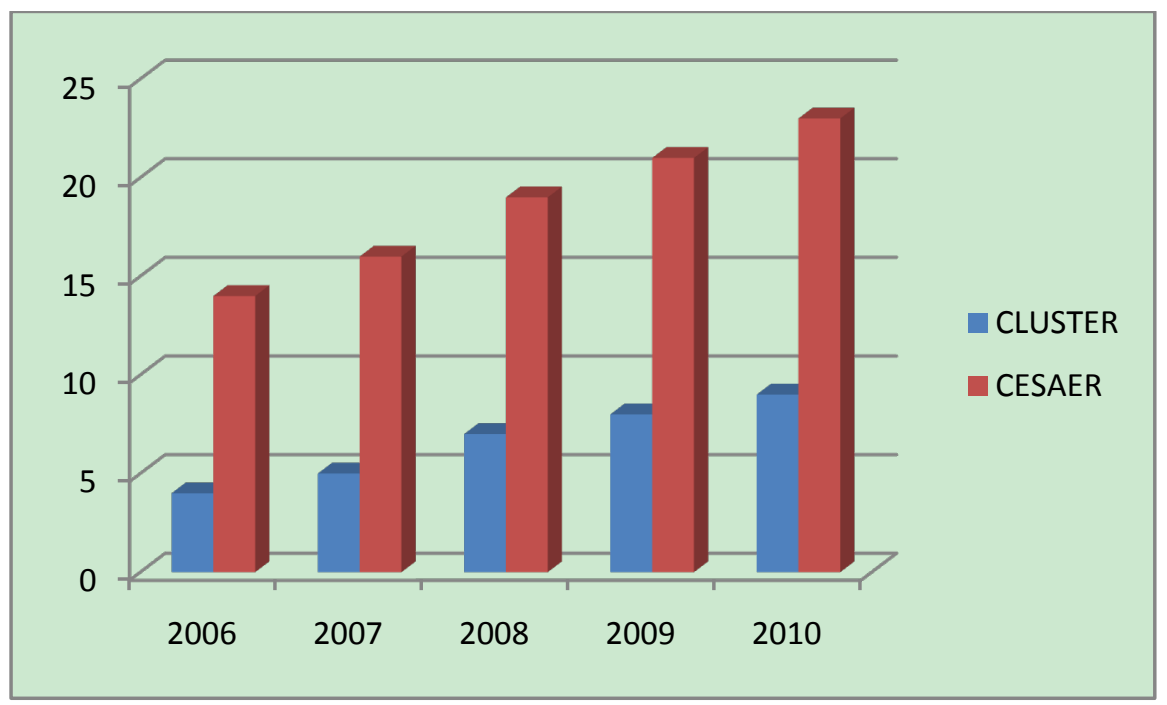

Figure 2. Dynamics of TPU bilateral cooperation within CLUSTER and CESAER

\section{Areas Of TPU Cooperation with European Universities of Technology}

The main areas of TPU cooperation with European universities of technology include:

- joint research projects,

- joint (double/dual) degree programs,

- students' academic mobility.

\subsection{Joint Research Projects}

Universities cooperation in fulfilling joint research projects is one of the key elements of their international activity and serves as a basis for development of cooperation in education, promotion of students' academic mobility, etc. Since 1990s, Tomsk Polytechnic University has been developing research contacts with leading technological universities of Germany, France, Great Britain, Czech Republic, Austria and other European countries.

Scientific cooperation of TPU with University of Karlsruhe (Germany) began in 1993 with joint research projects in power engineering and high voltage engineering. The cooperation progress was rather successful. In 1998 2004 TPU and University of Karlsruhe carried out two research projects on university management development within the framework of TEMPUS program: «University Management Guide» (150 thousands ECU) and «University Management» (270 thousands ECU).

At present scientific cooperation of TPU with Karlsruhe Institute of Technology (KIT) is focused on power engineering and electrical engineering, nanotechnologies, physics and ecology. In 2005 the German-Russian Centre for research in water ecology and water systems was established on the basis of TPU and KIT. The Center held 5 research seminars where results of joint research were discussed. In particular, the 2010 seminar was devoted to: «Modern Problems of Water Treatment and Nanoparticles in Water Bodies». Scientific exchange as part of activities of the
Center is financed via $D A A D$ grants, Baden-Wurttemberg scholarships, Russian Federation Government and Russian Federation Presidential scholarships.

In 2005 the TPU International Research Laboratory «Tribotechnical Problems of Material Hardening» was established in cooperation with Technical University of Berlin. The laboratory focuses on fundamental and applied research, develops devices, methods and technologies for triboacoustic and dynamic testing of materials. In 2008 the international seminar «Distribution and Parallel Computing, and Systems of Knowledge Processing» was held at TPU in cooperation with the Technical University of Munich. In 2010 the joint International Research Laboratory «Nuclear Technologies and Safety» concentrating on thermal-hydraulic study of nuclear reactor active zones was established.

Since 1992 TPU has been developing research cooperation with University of Saarland in the field of computer engineering, applied mathematics and material studies. In 2008 TPU together with the University of Saarland held an international seminar «Non-Destructive Testing». In 2010 the International Research Laboratory «Radiation Control and Diagnostics» was established at TPU in the partnership with University of Saarland and Fraunhofer Institute of Non-Destructive Testing under the auspices of Professor Hans-Michael Kroening who has been the TPU Honorary Professor since 1993.

Tomsk Polytechnic University is developing research cooperation with engineering universities of France, particularly in the field of nanotechnologies. TPU together with the Ecole Centrale Paris carries out research in the field of synthesis of nanofoliate tungsten and molybdenum disulfides. Research in the field of photoacoustic spectroscopy of nanodispersed aluminum and iron lyosols are carried in cooperation with Universite d'Orleans. TPU and Université Joseph Fourier run joint research project in the field of $2 D$ and $3 D$ - manipulation of submicron particles using nanotweezers in air and liquid media. TPU together 
with École Nationale Supérieure de Mécanique et d'Aérotechnique carries out research in the field of numerical modeling of heat and liquid transfer processes under stainless steel combustion.

Tomsk Polytechnic University develops cooperation with the Czech Technical University in Prague in the field of nanomaterials, charged particles plasma physics, medical physics, composite materials and alloys. For many years Tomsk Polytechnic University has been developing cooperation with the Vienna University of Technology (Austria): the universities exchange of research and technical information, organize joint seminars and conferences. In 2008 TPU and Irkutsk State Technical University held the international seminar «Quality of University Management and Bologna Process» organized in cooperation with Vienna University of Technology. In 2010 joint research and educational seminar $《{ }^{\text {th }}$ Framework Programme of Research under European Commission and International Research and Educational Cooperation» was held in Vienna.

Cooperation of Russian and European universities of technology within the EU Framework Programs is extremely important. As of August 20112233 applications together with partners of $F P 7$ from Russia were submitted (10\% of all applications together with «third world countries» partners), $429(9,49 \%)$ of them were successful. The research organizations of the Russian Academy of Sciences demonstrate more active participation in the Framework Programs of the European Commission. Russian universities of technology are participating less in international projects financed by EU Framework Programs.

In order to make EU Framework Programs more popular among Russian technical universities, a number of infrastructure projects were carried out with TPU involvement. From 1998 to 2000 Tomsk Polytechnic University participated in ENRIN Project (FP4) «Establishment of a Network of Regional Information Nodes on IT-RTD in Russia» which established and trained 10 regional contact points across Russia to promote the IST Priority in FP5. It compiled a database of Russian research teams classified to IST Action Lines for partner search and provided limited support in arranging meetings between research teams. From 2003 to 2005 Tomsk Polytechnic University participated in TRISTAN-EAST Project (FP5, €1.1 $\mathrm{mln}$ ) which aimed to train and mentor intermediaries, chiefly commercial consultancies, who would promote the IST Priority and assist proposers in many countries in eastern Europe, including Russia.

From 2004 to 2006 Tomsk Polytechnic University participated in SITE Project (FP6, €450,000). The objective of SITE Project was to increase cooperation between Russian and EU researchers in the area of the IST Priority. The project was focused on the Siberian region of Russia. The results of the project were as followed:

- eight Regional Centers and 56 European Offices within Russian organizations with substantial research expertise in IST were trained so that they could explain how Russian research teams can participate in the IST Priority,

- a partnering database of profiles of 320 Russian research teams was developed,

- partnering activity helped to establish 20 continuing relationships between research teams in the EU and Russia,

- ten joint EU-Russian teams were assisted in proposal preparation.

From 2004 to 2005 Tomsk Polytechnic University participated in RUSERA Project (FP6-INCO, €121,050). The Russian Association for Engineering Education coordinated the Project aimed at contributing actively to the FP6 strategic objectives by fostering the collaboration between the EU and Russia within the FP6 with a special focus on the topics of the INCO Program. The Project provided RTD-cooperation between the advanced and promising Russian regions and the EU research organizations by establishing a network of Regional Information Nodes (RIN) in 37 Russian Regions all over the country. The RINs collected nearly a thousand profiles of regional research teams, and have helped to create 447 partner search profiles on CORDIS. Dozens of potential partners within the EU have been identified, with 47 project consortia being formed and 17 project proposals submitted to the Commission.

From 2007 to 2008 Tomsk Polytechnic University participated in RUSERA-EXE Project (FP6-INCO, $€ 245,972)$. The Russian Association for Engineering Education coordinated the Project. The Project objective was to increase the quantity and quality of cooperation between Russian and EU researchers by creating long lasting "researcher-to-researcher" RTD partnerships. RUSERA-EXE Project final results were as followed:

- 47 long-lasting contacts in total were established, 18 project proposals were submitted (3 joint project proposals were approved for funding),

- RUSERA-EXE Handbook for Russian and European Researchers and Research Managers was created.

Since 2009 Tomsk Polytechnic University has been participating in ACCESSRU Project (FP7, €558,522 for 30 months). ACCESSRU has the following objectives:

- to assess access opportunities in Russia for EU organisations, by screening of Russian S\&T landscape and identifying common challenges, needs and opportunities in S\&T in both sides,

- to raise awareness on access opportunities in Russia amongst European research organizations and to stimulate, encourage and facilitate the participation of European organisations in Russian programs,

- to enhance the S\&T policy dialogue and to formulate the strategic recommendations on scientific collaboration between Europe and Russia, ensuring the reciprocity issues.

Since 2009 Tomsk Polytechnic University has been participating in NEPHH Project (FP7, €3,186,530, for 36 months). Coordinator: EKOTEK (Spain). The consortium taking part in the Project is made up of ten entities from seven countries, amongst which there are important benchmark references in nanotechnology research such as 
the University of Cranfield (UK), the Cracow University of Technology (Poland), etc. The Project aims at evaluating impact of Nanotechnologies on health and the environment.

\subsection{Joint Academic Programs}

Development and implementation of joint academic programs is one of the Bologna Process priorities. In accordance with the Transatlantic degree Programs Survey 2009 data, European universities have implemented more than 700 joint programs including 126 bachelor programs, 548 master programs, and $127 \mathrm{PhD}$ programs. Universities of France (38\%), Germany (22\%) and Great Britain (16\%) are considered to be the most active in joint programs development.

One of the key tools aimed at sustainable European cooperation development in higher education is ERASMUS MUNDUS Program which was launched in 2004. In the framework of ERASMUS MUNDUS Program 133 joint master's programs and $34 \mathrm{PhD}$ programs were developed. According to the European commission statistics more than 400 citizens of the Russian Federation took part of their studies within ERASMUS MUNDUS joint programs.

Joint education programs provide high quality of graduates' training preparing them for professional activities [15]. This is accomplished by the integration of material and intellectual resources of partner universities. Education at foreign universities in the framework of joint programs promotes the development of graduates' communication competences and their readiness for international professional mobility.

Development and implementation of joint programs is one of the key indicators of innovative activity of Russian universities. According to recent social studies, $85 \%$ of Russian universities understand the need for development of joint/double/dual degree programs. According to studies, 79 Russian universities implemented 246 Double Degree programs with European universities (excluding joint $M B A$ programs): $65 \%$ of programs are at master level and $6 \%$ of programs are at $P h D$ level. Most of these programs are in economics and management (45\%) as well as in engineering (36\%). Double Degree programs are developed in cooperation with partner universities of Germany $(20 \%)$, France (13\%) and Great Britain (9\%).

Over the past decade Tomsk Polytechnic University has been developing and implementing joint programs with leading European universities. In 2001, the first master's programme in petroleum engineering was designed with Heriot-Watt University (HWU, Great Britain). At the end of this 2-year programme graduates are awarded with two degrees: Master of Sciences in Petroleum Engineering at TPU and Master of Sciences in Petroleum Engineering at $H W U$. For the time being, more than 600 graduates of this program are successfully employed by leading Russian and international oil and gas companies. In 201170 students were enrolled in $T P U-H W U$ study programme. According to competition result there were 13 applicants for one place. The interest in the program is constantly growing. The dynamics of students' interest growth is given below (Fig.3).

The TPU $-H W U$ Petroleum Learning Center also delivers short-term CPD programs and courses for employees of oil and gas companies, carries out research projects for both Russian and foreign oil companies, such as RosNeft, GaspromNeft, TNK-BP, Schlumberger, Baker Hughes.

Since 2007 TPU has started to develop Double Degree master programs with universities of Germany. The first Double Degree master program «Physics of High Technology in Mechanical Engineering» was developed in cooperation with Technical University of Berlin. Mutual research and engineering developments of TPU's Mechanical Engineering Department and Faculty $V$ Mechanical Engineering and Transport System of the Technical University of Berlin served a basis for joint program.

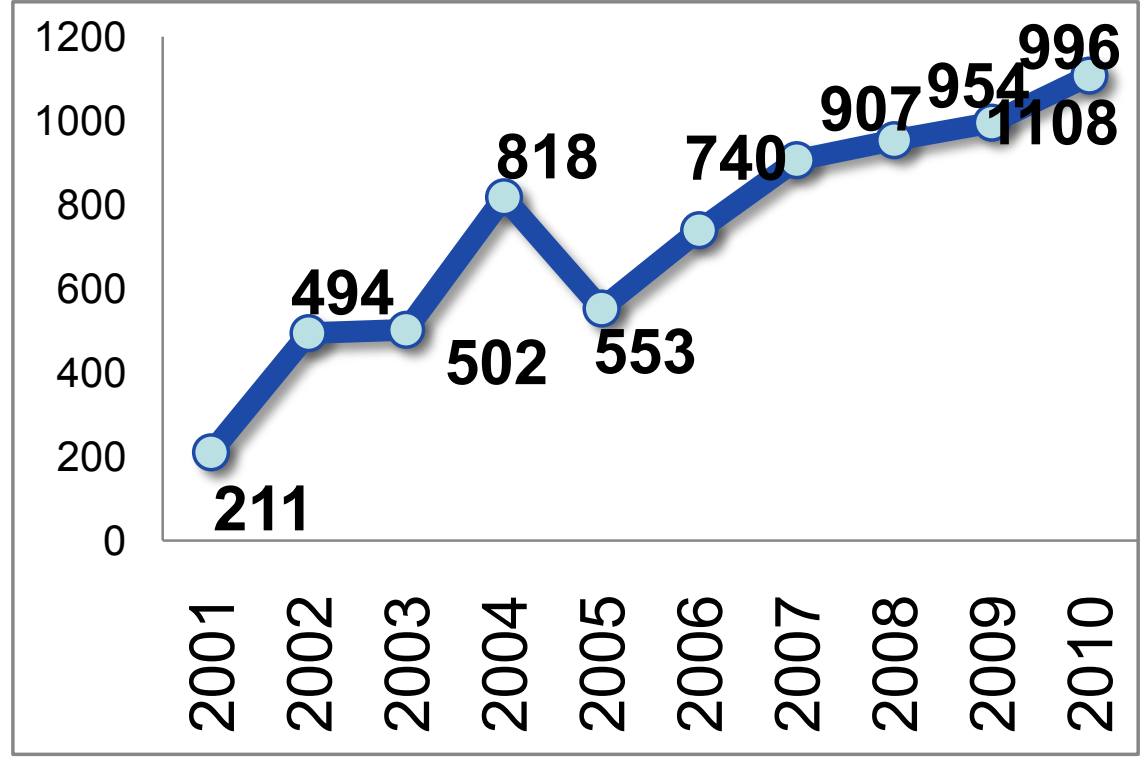

Figure 3. Dynamics of students' interest growth (TPU-HWU Double Degree program) 
In 2008 Double Degree programme «Computer Networks and Telecommunications» was developed by TPU in cooperation with Technical University of Munich (Germany). Since 2009 TPU has been implementing «Modernization of Master Program Network \& Communication» Project within the framework of TEMPUS Program. The grant holder and Project coordinator is Technical University of Munich. Tomsk Polytechnic University is the Project coordinator for partner universities in Russia. The project is carried out by the consortium of universities including two European universities: Catalan Polytechnic University (Barcelona, Spain) and New University of Lisbon (Portugal) and three Russian universities as well: National Research Irkutsk State Technical University, National Research Moscow State Institute of Electronic Technology and Siberian Federal University.

In 2010 Dual Degree Program «Power Generation and Transportation» was developed in cooperation with Technical University in Prague (CTU, Czech Republic). In accordance with the agreement, program graduates are granted with TPU Master of Science Degree in Power Engineering, and CTU Master of Science degree in Electrical
Engineering, Power Engineering and Management.

The other Double Degree Programs developed by TPU in cooperation with European universities include «High Voltage Engineering and Physics» (Aachen University of Applied Sciences, Germany), "Environmental Problems in Geology» (University Paris 11, France), etc. To enhance the quality of academic programs TPU is running two TEMPUS projects, i.e.: «Engineering Curricula Design aligned with $E Q F$ and EUR-ACE Standards» (coordinator - Wismar University of Applied Sciences, Germany) and «International Master Program «Tourism» for Siberian regions», (coordinator - Aalborg University, Denmark).

\subsection{Students' Academic Mobility}

One of the Bologna Process priorities is the development of students' academic mobility. The lack of national strategy on international cooperation in education as well as lack of money allocated for marketing and infrastructure development is the main barriers on the way to academic mobility development in Russia.

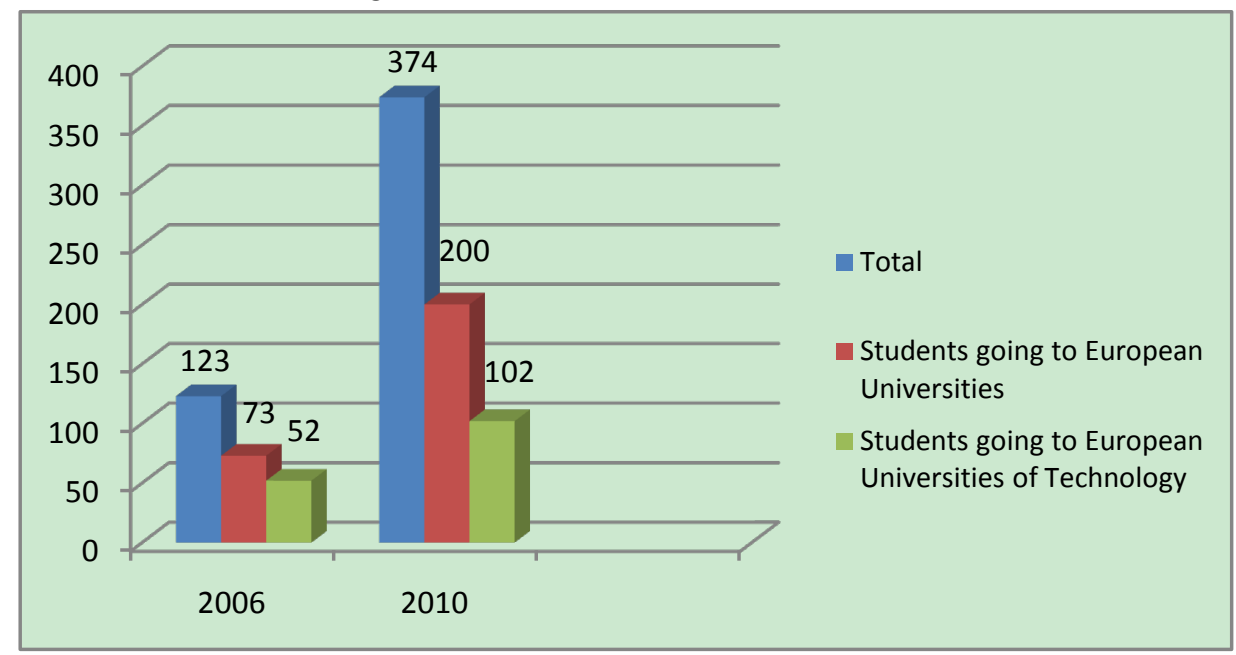

Figure 4. Outgoing TPU students' international mobility

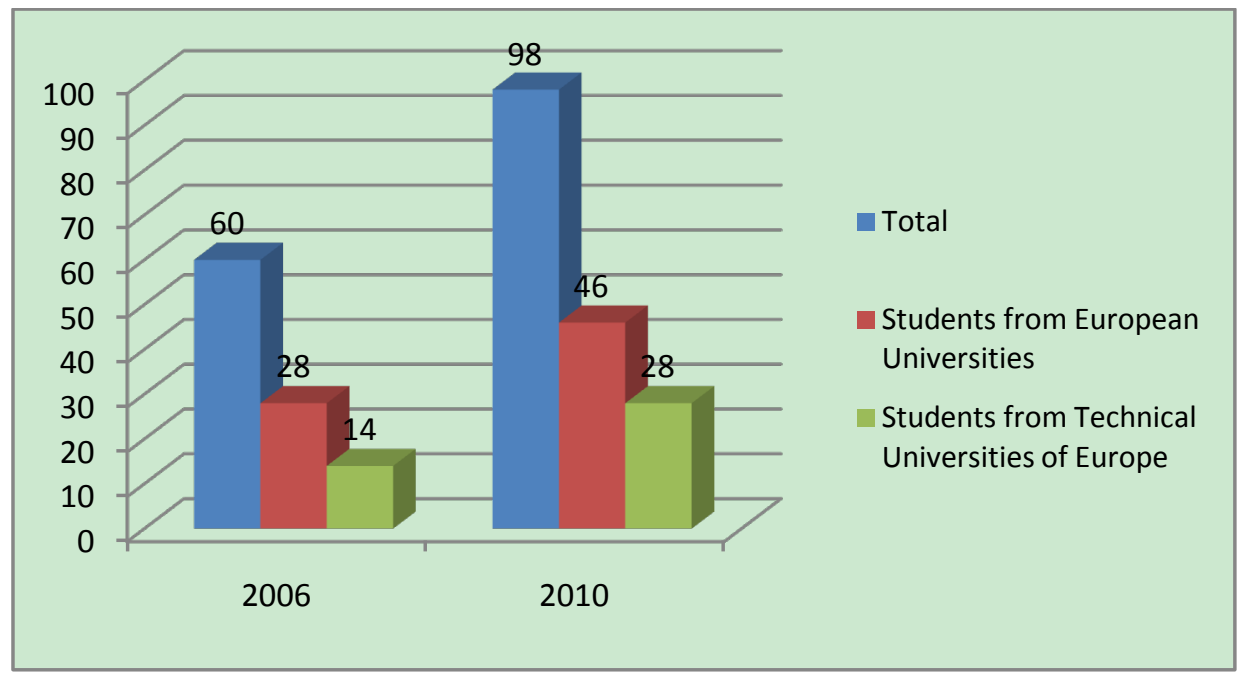

Figure 5. Incoming international students' mobility at TPU 
However development of international academic mobility is one of the TPU strategic aims. Tomsk Polytechnic University has signed 55 bilateral agreements with foreign universities for students' exchange (44 of them have been signed with European universities). The existing TPU system of international academic mobility allowed tripling the number of exchange students for the period of five years and enlarging the scale of the programs and projects: T.I.M.E., ERASMUS MUNDUS, TEMPUS.

The most successful and effective academic mobility programs have been developed with the following European universities: Czech Technical University in Prague (Czech Republic), Vienna University of Technology (Austria), Muni ch University of Technology (Germany), Grande Ecoles of ParisTech (France).

Since 2007 the European Commission has approved 13 projects on cooperation with Russia in the framework of ERASMUS MUNDUS Programs (ERASMUS MUNDUS EXTERNAL COOPERATION WINDOW 2007-2009, ER ASMUS MUNDUS 2009-2013, Action 2 Erasmus Mundus Partnerships between European and Third Country Higher Education Institutions) [8]. Starting from 2008 Tomsk Polytechnic University has taken part in three projects initiated by ERASMUS MUNDUS Program as a part of consortium coordinated by Dresden University of Technolo gy (Germany). Within the framework of these projects 36 students of TPU took part of their studies at University of Trento, Technical University of Vienna, University of Rome «La Sapienza», Technical University of Dresden and others. Dozen students from European universities studied at TPU. In 2012 Tomsk Polytechnic University will continue participation in ERASMUS MUNDUS MULTIC Project.

Development of academic mobility programs is an important step towards the development of mutually beneficial cooperation between Russian and European universities in education and research areas. Tomsk Polytechnic University is proud to be one of the most active Russian technical universities developing international cooperation with European universities of technology.

\section{Conclusions}

There are no doubts that nowadays international cooperation is having an increasing impact on all aspects of university life. It is considered to be an instrument to improve education and research. For many Russian universities and Tomsk Polytechnic University is not exclusion working with European partners is an integral part of internationalization. Among the main areas of cooperation it is worth to highlight academic mobility, joint degree programs and research cooperation. However sometimes strategy of international cooperation lacks systematic approach and more defined targets. Nonetheless we have all the grounds to believe that the international links with European partners will only become stronger in future, moreover considering the EHEA development.

\section{REFERENCES}

[1] http://www.tpu.ru National Research Tomsk Polytechnic University.

[2] http://www.aeer.ru Association for Engineering Education of Russia.

[3] http://www.ac-raee.ru Association for Engineering Education of Russia Accreditation Center.

[4] http://www.enaee.eu European Network for Accreditation of Engineering Education.

[5] http://www.feani.org European Federation of National Engineering Associations.

[6] http://www.ApecRegister.tpu.ru Russian Certification Center of the APEC Engineer Register.

[7] http://www.ieagreements.org/APEC/signatories.cfm APEC Engineer Register.

[8] http://ec.europa.eu/education/external-relation-programmes/ mundus_en.htm Erasmus Mundus Scholarships and Academi c Cooperation.

[9] Chuchalin A., Boev O., Kuznetsova E. Quality Standards for Russian Higher Engineering Education // Proc. 37 $7^{\text {th }}$ Intern. Symp. IGIP, Moscow, 2008, pp. 4-9.

[10] Chuchalin A. Zamyatin A. Higher Education Institution Quality Management System. International Journal of Quality Assurance in Engineering and Technology Education, 1(1), January-June, 2011, p.30-43.

[11] Chuchalin A., Boev O., Kuznetsova E. The Implementation of European Standards for Accreditation of Engineering Programs in Russia // Book of Abstracts, $36^{\text {th }}$ Annual SEFI Conference, 2-5 July, 2008, Aalborg, Denmark, p. 66.

[12] Chuchalin A., Minin M., Safyannikov I. Innovative University Teachers Training in Up-to-Date Technologies of Engineering Education // Proc. 38th Intern. Symp. IGIP, Graz, 2009, pp. 118-120.

[13] Chuchalin A.I., Boev O.V., Kriushova A.A. Quality Assurance in Engineering Education and Modernization of Higher Education in Russia // Engineering Education Quality Assurance, Springer Science+Business Media, LLC, 2009, pp. 87-95.

[14] Chuchalin A.I., Boev O., Gerasimov S., Kriushova A. Developing Professional Accreditation of the Engineering Education in Russia // International Higher Education Research, Vol. X, Jan., 2010, Sapporo, Japan, pp. 59-63.

[15] Chuchalin A.I., Minin M., Boev O. Criteria of Conformity of Educational Programs in Engineering and Technology to International Standards // Proc. of the Joint Int. IGIP-SEFI Annual Conf. 2010 "Diversity unifies - Diversity in Engineering Education”, 19-22 Sept., 2010, Trnava, Slovakia, pp. $48-49$.

[16] John Taylor. Structuring Internationalisation: The Role of the International Office // Internationalisation of European Higher Education. V. 11, April 2012, RAABE. 